\title{
Perspectives of Headteachers, Teachers, Parents and Caregivers about Early Childhood \\ Education Program in Punjab: A Qualitative Study
}

\author{
* Saima Malik, PhD Scholar (Corresponding Author) \\ ** Muhammad Zaheer Asghar, Assistant Professor \\ *** Laila Khalid, PhD Scholar
}

\begin{abstract}
This study was aimed to investigate the perspectives of headteachers, teachers, caregivers, and parents about the prevailing Early Childhood Education (ECE) program in public schools of Punjab. Participants of the study were selected through a convenient sampling technique. Semi-structured interviews were conducted with 6 headteachers, 6 teachers, 3 caregivers, and 3 parents. Qualitative content analysis was used to analyze the collected data. All data related to eighteen participants were coded. Clustering similar codes helped in identifying sub-categories from data. Several assertions were developed by comparing and contrasting various categories and sub-categories. The findings of this research highlighted the missing facilities of ECE in public schools i.e. separate ECE rooms, trained ECE teachers, absence of caregivers, unavailability of a separate budget for ECE, provision of ECE kit, well-equipped playgrounds, reluctant behavior of teachers as well as parents dissatisfaction with teachers' performance. The results of the study are useful for policymakers, administration of the Quaid-e-Azam Academy for Educational Development (QAED) to develop the program.
\end{abstract}

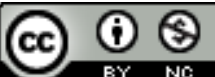

Keywords: Early Childhood Education, ECE Practices, Parents, Caregivers, Punjab

\section{Introduction}

Early Childhood Education (ECE) plays a vital role in the holistic development of a child (Bhutta, 2020; Saif, Inam \& Abiodullah, 2020). It is recognized globally and all countries of the world are focusing on it specifically (UNESCO, 2019). Education for All (EFA), Millennium Development Goals (MDGs), Universal Primary Education (UPE), and Sustainable Development Goals (SDGs) are the subsequent international commitments towards ECE (MoE, 2017). As being a signatory to these international commitments, Pakistan is offering ECE in the form of pre-primary education with the name of "Katchi class" for 3-5 years old children in public schools of Pakistan (Khan, 2018). The National Education Policy (NEP) 2009, the National Education Policy (NEP) 2017, and Article 25-A of the $18^{\text {th }}$ Amendment (April 2010) have put a special focus on early childhood education (Ahmed, Anjum \& Rehman, 2015; Khan, 2018).

As being a partner of all the above-mentioned international commitments, the province "Punjab" is also making extensive efforts to spread ECE over its territory (Farooq, 2018). The Quaid-eAzam Academy for Educational Development (QAED), school education department had launched the ECE program in Punjab in the year 2013 w ith the slogan of "Child-Friendly Schools (CFSs)" in all nine divisions and 36 districts (QAED, 2019). Punjab has presented its ECE policy with the title "Punjab ECE policy (PECEP) 2017" which declares " ECE" as a source of improvement in retention rate and drop-out ratio before enrolling in formal Grade I (Ismail \& Awan, 2019).

However, the prophesied targets of assuring the high enrolment in ECE are steadily underachieved all over Pakistan as well as in Punjab too (Bhutta, 2020). Out of school children and high drop-out ratios at the primary level is the major problem in Punjab (Shah, Haider, \& Taj, 2019). ECE has not proved a valuable source to control the causes due to having an enormous difference between policy and implementation in Punjab (Arshad \& Zamir, 2018). The only four days training program is being imparted to the in-service teachers, headteachers, and caregivers to run the program in Punjab by the Government of Punjab through QAED (GoPb, 2017).

\footnotetext{
* Department of Education, University of Management and Technology, Lahore

** Department of Education, University of Management and Technology, Lahore

$* * * \mathrm{UMT}$
} 
QAED has established ECE classrooms across 36 districts of Punjab with the support of donor agencies i.e., UNICEF and PMIU. Newly ECE classrooms along with trained in-service ECE teachers could not increase the enrollment ratio in public schools of Punjab as compared to private schools $(\mathrm{GoPb}, 2017)$. The current provision of ECE has placed a question mark upon the given quality of public schools (Ghazi, Ajmal \& Saeed, 2018; Ismail \& Awan, 2019). ECE program has not proved a source of increasing the enrollment and retention rate at the primary level in Pakistan as well as in Punjab. Most of the studies conducted for the evaluation of the ECE program in Punjab were mainly focused on teachers and facilities but ignored parents and caregivers, which is the central point of this research study as their perception and satisfaction have been studied in the research. Therefore, it was necessary to investigate the prevailing practices, so that the existed differences and deficiencies among the public schools may be explored.

\section{Obiective}

The objective of this study was to:

1. Investigate the perspectives of headteachers, teachers, caregivers, and parents about the prevailing ECE program in public schools of Punjab.

\section{Research Questions}

The following research questions were followed in this study:

1. What are the main factors that influence the quality of the ECE Program in public schools?

2. What is the benefit of hiring caregivers for ECE in Public schools?

3. How many parents are satisfied with the ECE program in public schools?

4. What are the suggested measures to improve the quality of public ECE schools?

\section{Review of Related Literature}

ECE is considered a crucial stage for the sustainable development of children (Thornton 2019). Research has proved that in this period, the mental development of a child is extraordinarily fast as compare to the rest of the life span, and learning is found by instinct in a child (Lipman, 2018). According to UNICEF's global report on early childhood growth, (2017), "a child's first five years of life are crucial in laying the foundation for success in later life due to the development of 90 percent of the brain during this period". ECE initiatives have proven to be a valuable tool in the fight against hunger, malnutrition, and education shortages in developing countries around the world (UNICEF, 2018). Educational researches recommended that early childhood education had a long-term and short-term relationship with an individual's positive behavior, and it leads to success in life (Franchett et al., 2019). The adults who had earned an education at an early age are less likely to engage in risky or dangerous behavior. Not only is this rather ECE proved as a change agent to change the adverse outcomes of poverty (Bailey, Duncan \& Odgers, 2017; Jenkins \& Duncen, 2017; UNICEF, 2019). All the international pledges i.e. EFA, UPE, MDGs, and SDGs 4 elevated the need and importance of ECE. SDG4 has recently received international recognition for providing inclusive and equal quality education as well as the promotion of lifelong learning opportunities for all (UNICEF, 2019).

Empirical evidence supports the value of high-quality early childhood education services in establishing a meaningful learning cycle that lasts far into the early years of a child's education (NAEYC, 2015). ECE is an uttermost stage of life where there is a huge chance of return of higher rates of human capital compared to investment at any other stage of life (Hunkin, 2018). Quality ECE services are a prerequisite for closing achievement gaps created by poverty and assisting the most disadvantaged children (UNICEF, 2019). National Association for the Education of Young Children (NAEYC) has described the definition of the quality ECE, and it states that implementing a highquality ECE program results in the development of various skills in young children, including academic, language, physical, social, and emotional development. These acquired skills prepare them for school and lay the groundwork for subsequent academic and social success (NAEYC, 2018). The programs which emphasize safety and nurturing environments besides supporting the development of all developmental domains while meeting the needs of families can be included in the ranking of high-quality ECE programs. Additionally, high-quality ECE includes structural and process measures that include teachers' characteristics, class ratio, instructional support, and specific features of a program (Acosta, 2018). The standard of education given to children in ECE programs helps them improve language, math, and social skills at a young age, which can have a huge impact on their ability to learn for the rest of their lives (Green, 2013). Critical thinking, collaboration, resilience, and creativity can be developed through the high-quality ECE program as per the demand of the modern 
job market (UNICEF, 2019). Pianta, (2011) indicated that the effectiveness and quality of ECE could be enhanced by providing natural settings which provide ample chance of activities that give children choices to explore and play.

The report of UNICEF, (2019) describes, "Adolescents in 2030 are still in the early stages of puberty, on the verge of starting primary school. Quality pre-primary education is one of the best investments they can make to ensure their future success and that of their children and grandchildren". It further depicts, "The advantages of quality pre-primary education reach far beyond individual children's formal acquisition of academic qualifications and they also help a country's long-term aspirations for economic development" (UNICEF, 2019).

Studies have shown that children who attend high-quality early education programs have more cognitive, health, socio-emotional, and behavioral outcomes as compared to those children who do not have early education experiences (Camilli, Vargas, Ryan, \& Barnett, 2010; Levi et al., 2015; Lipman, 2018; Thornton, 2019; U.S. Department of Health and Human Services \& U.S. Department of Education, 2016; Valentino \& Stipek, 2016). There are several studies which had highlighted the importance of providing not only early education rather than quality early childhood education (Bishop, Maier, Melnick, \& Wechsler, 2016; Friedman-Krauss, Barnett, \& Nores, 2016; Johnson, 2016; NAEYC, 1995; NAEYC, 2006; NAEYC, 2018; Stevens \& English 2016; Thornton, 2019). These studies identified several building blocks of quality early childhood education, i.e., inclusive early learning curricula, activity-based learning, ongoing support and training of ECE teachers, appropriate child assessments, the opportunity for diversity in learning of young kids, family engagement, ample time, appropriate class size, adequate teacher-student ratio (Bishop, Maier, Melnick, \& Wechsler, 2016; Pelot, 2018).

All the above-mentioned studies have highlighted the need and importance of not only an ECE program but a quality ECE program. In Pakistan and Punjab too, the ECE program has not proved a source of increasing the enrollment and retention rate at the primary level. Most of the studies conducted for the evaluation of the ECE program in Punjab were mainly focused on teachers and facilities but ignored parents and caregivers, which is the central point of this research study as their perception and satisfaction have been studied in the research. This study attempted to fill the gap in the literature.

\section{Methodology}

This study was aimed to investigate the perspectives of headteachers, teachers, caregivers, and parents about the prevailing ECE program in public schools of Punjab.

A qualitative research approach was used in this study. Qualitative research is an important way to investigate the meanings people ascribe to events and is one of the ways of learning about social reality (Mason, 2018; Patton, 2015). This study used what Merriam (2009) refers to as a simple qualitative study research design, which is used to investigate "how people make sense of their lives and their experiences" (Merriam, 2009).

\section{Participants}

Participants of the study were selected through a convenient sampling technique during the pandemic "COVID-19". The researcher interviewed six headteachers, six teachers, three caregivers, and three parents from urban and rural areas of Punjab.

\section{Instrumentation}

Self-developed separate interview protocols based on the interventions of QAED were used to collect data from headteachers, teachers, caregivers, and parents. Interview guides were validated by the experts in the field. The respondents were asked about dominant ECE program in public schools in terms of ECE infrastructure, advantages of ECE program in public schools, the usefulness of imparted training to in-service teachers and headteachers, benefits of hiring and imparting training to caregivers, responsibilities of caregivers in the ECE classroom, involvement of parents in ECE and suggestions for the improvement of the prevailing program.

\section{Analysis}

All the conducted interviews with headteachers, teachers, caregivers, and parents were analyzed using qualitative content analysis (Schreier, 2012). Interviews were translated and transcribed by us ing tape recordings. The transcriptions were precise and checked by an expert in the English language (Creswell, 2007). Data related to the participants have coded before clustering similar codes for identifying the categories and sub-categories (Saldaña, 2013). The process of comparing and 
contrasting categories and sub-categories developed several assertions (Miles, Huberman \& Saldaña, 2014). Those assertions in the form of themes are reported in the section of findings.

Table 1

Demographic Information of Participants

\begin{tabular}{lll}
\hline Participants & Gender & Designation \\
\hline Participant 1 & Male & Headteacher \\
Participant 2 & Male & Headteacher \\
Participant 3 & Male & Headteacher \\
Participant 4 & Female & Headteacher \\
Participant 5 & Female & Headteacher \\
Participant 6 & Female & Headteacher \\
Participant 7 & Male & Teacher \\
Participant 8 & Male & Teacher \\
Participant 9 & Male & Teacher \\
Participant 10 & Female & Teacher \\
Participant 11 & Female & Teacher \\
Participant 12 & Female & Teacher \\
Participant 13 & Female & Caregiver \\
Participant 14 & Female & Caregiver \\
Participant 15 & Female & Caregiver \\
Participant 16 & Female & Mother \\
Participant 17 & Male & Father \\
Participant 18 & Male & Father \\
\hline
\end{tabular}

Results

ECE Infrastructure

The shortage of rooms in public schools was reported by all the participants as the major dilemma. Firstly, managing a separate classroom for ECE is tough and if it is allocated by all means then management of instructed six corners (by QAED) in the classroom of ECE is not possible due to insufficient place within the classroom. One of the headteacher participants informed that "My school has a total of four rooms. One of which is designated for ECE. However, owing to management and the rest of the classes, it could not run any longer". (Participant 1)

In-service trained ECE teachers couldn't continue their services to ECE class due to a shortage of teachers in public schools. Almost all the teachers complained about not assigned ECE classes for teaching by the headteacher. "I have taught ECE class only for three months after training. Headteacher had assigned another matric pass untrained teacher to teach ECE class. Because she couldn't teach higher classes". (Participant 3)

QAED had distributed an ECE kit to manage activity-based learning in the ECE schools. But most of the schools had complained about the unavailability of this facility. One of the teacher participants stated that "The provision of ECE kit by QAED must be complimentary in any ECE school; activities cannot be managed without it. Two years have passed since the training, but we still haven't received the ECE kit". (Participant 7)

\section{Advantages of ECE Program in Public Schools}

All the participants accepted the importance of launching ECE in public schools. They expressed their views by considering it a very good program. Now the children of a government school also enjoy their studies like a child in a private school. UPE targets are going to be achieved due to the launching of the ECE program in our public schools. But this effective and important program requires sincere management to be successful. Whenever any program launches are quite beneficial for society. But it depends on the administration that how much it takes interest and responsibility to lead it towards accomplishment.

All the participants endorsed the importance of starting ECE in public schools. One of the participants said,

ECE is a very effective program. As compare with the past, now we are in a good position of enrollment. After getting ECE now a child is well trained for class one. Now we can compare our children with the students of a private school because of the starting of ECE. The ECE room is well decorated. Children of ECE come with excitement e.g. in my school children enjoy their time by watching learning material on the LED. In the beginning, I had invited all mothers from my village to 
visit the ECE classroom. After their visit, a few of them enrolled their children in my school after taking a school leave certificate from a private school. (Participant 9)

\section{The Usefulness of Imparted Training to In-Service Teachers and Headteachers}

All the participants of this study have acknowledged the effectiveness of imparting training in terms of satisfaction with the trainer, presented content and facilities during training sessions. But they have pointed out a lack of resources to implement the learned skill in public schools. Which hinders the success of the program. Further, they complain about the mental approach of organizers of the training sessions. They are from the standpoint that trainers, as well as organizers, do not know the actual prevailing conditions of our public schools, especially the schools which are located in rural areas. One of the headteacher participants discussed it as under

It was very effective in terms of knowledge but practically it is not possible to implement at all due to a shortage of resources in our public schools. During training, trainees get very excited but when they go back to the field they have complaints of having scarce resources" (participant 6).

\section{Benefits of Hiring and imparting training to Caregivers}

All the participants acknowledge the importance of the role of caregivers for ECE. The role of caregiver is very beneficial for our schools. The caregiver has become a chain and an ambassador between school and community for public schools. The teachers become uneasy when the caregiver gets on leave. The government has owed only RS: 4000/ salary for a caregiver. Which is quite beneficial for the government. The government is paying RS: 35000/ to a Primary School Teacher (PST) but practically the duty of a caregiver is the same as a teacher of ECE. But all almost all the participants have complained about the unavailability of allocated budget for the hiring of trained caregivers. One of the participants elaborated that

I can't hire a trained caregiver because of the shortage of budget. The government has not given us funds to pay the salary to a caregiver. Government has decided Rs: 4000/per month to pay caregiver but practically has not allocated budget" (Participant 5).

\section{Responsibilities of Care givers in the ECE Classroom}

It is the foremost dilemma of our public schools that most of the teachers are not interested to teach. They prefer to spend their time gossiping. Their concern is with just the pay not work. All the caregiver participants recounted the reluctant attitude of permanent teachers towards teaching young kids. One of the participants illustrated:

The overall responsibilities of kids have lied on my shoulders. The permanent teacher was not serious about teaching. She was used to roaming around the whole school. She did not take interest in teaching. Even any official school visits then I told him about the total strength of students. Even she did not know how many kids are there present in her class. (Participant 13)

\section{Involvement of Parents in ECE}

The satisfaction of the parents is the key pillar of any school system. When there is a nest of private schools in surroundings then there is a strong need emerge to satisfy the parents of a child in public school. The need and importance of ECE are recognized by all the parent participants of this study. ECE is the foundation of learning. A mind of a young child is easier to be filled with knowledge at an early age as compared with later stages of life.

Most of the parent participants have objections to the arrogance of teachers at the ECE level for example one of the participants illustrated:

"There is no attention given to my kid at school. Only caregivers attend 100 students in the classroom. We pay to focus on him at home. There is no lesson of ethics at school. My son does not like to go to school. The behavior of his teacher is very strict. His teacher usually punishes him for not doing homework. How is it possible for a child of 4 years to do homework efficiently? These are the major flaws of public schools. That's why parents want to get admission of their kids at private schools as compared with public schools". (Participant 17)

\section{Suggestions for the Improvement of the Pre vailing Program}

All the partic ipants acknowledged the need and importance of the ECE program in our public schools. Constant training for ECE teachers is required desperately. Start a program is easy but keeping it updated becomes tough. So government should focus to facilitate the schools and provision of a budget to maintain the quality of ECE. There is underpinned the need of hiring separate qualified ECE teachers and caregivers to get the best results of the program. One of the participants complained about the feasibility of the program by mentioning that: "Trainers assume the ideal situation is lying 
in our schools but the actual situation of our public schools is entirely different which makes the program ineffective" (participant 5).

One of the participants reported that

This is an excellent program but the reason behind its failure is the selection criteria of the schools and staff. Those teachers are being trained where are not available separate rooms as well as facilities for ECE in the school. Proper feasibility should be checked before the selection of staff for training (Participant 10).

All the participants suggested hiring separate ECE teachers who will be masters in their fields to get the maximum benefits from the program. One of the participants said,

A specialized teacher in ECE can best handle the young kids. There are so many universities that are graduating thousands of ECE graduates annually. Then why the government does not hire them. They will be well trained and constant training for them is not necessary. Thus the government will save her time as well as budget too. (Participant 11)

\section{Discussion and Conclusion}

Empirical studies highlighted the need for professional development of ECE teachers and provision of physical facilities e.g. the findings of the study of Kimmel, (2020) endorse the need for professional development (PD) programs for ECE administrators and teachers for the improvement of instructor quality and professional plans which must include goals and an action plan to achieve these goals. The study conducted by Kashar, (2018) and Polly et al., (2017) also authenticates PD as an improvement or change in teaching practices of teachers toward the goal of improving students' learning and a source of a strong relationship between teacher's PD of learning and the positive impact of PD on student's learning. Different studies conducted by Akiba \& Liang, 2016; Hall et al., 2017; Polly et al., 2017; Yurtseven \& Altun, 2017 find the relationship between teachers' PD and student's learning (Gilbert, 2020).

The overarching focus of this study was to measure the effectiveness of early childhood education programs for public schools of Punjab. QAED has designed a mechanism of 4 days of training for the in-service teachers for teaching at the ECE level, headteachers to manage ECE in schools as well as caregivers to assist the ECE teachers. The findings of interviews with teachers' headteachers and caregivers indicated that allocation of separate ECE room and teacher became very tough in all the public schools. Shortage of rooms was reported in schools. Participants have elaborated it impossible to manage instructed six corners in the classroom of ECE as per instruction of QAED. Spearing the trained teacher for teaching in ECE was seen as tough for the headteachers due to having a shortage of enough numbers of teachers in overall the schools. All the participants reported that the enrollment in ECE has been increased due to having an attractive environment in the classrooms of ECE with the placement of the LED in the classroom and thematic colored walls of the rooms are fascinating for parents as well as for their kids. The children of a government school also enjoy their studies like a child in a private school. But this effective and important program requires sincere management to be successful.

Interviews conducted with parents highlighted the desire of parents on the need for ECE for the children at an early age. They think that ECE can be the ultimate productive when there will be an attractive environment in the schools. A child-friendly environment engages the children longer in the process of learning. The participants of this study have complained about the reluctant behavior of teachers in public schools. Mostly, ECE teachers show less concern with the child's performance in schools.

\section{Recommendation}

Based on the findings of this study, the below-mentioned suggestions were made:

1. The government should allocate special budgets and resources for ECE in all public schools.

2. Qualified ECE teachers should be hired specifically for teaching at the ECE level.

3. Only trained in-service ECE teachers should be allocated by the headteachers for teaching at the level of ECE.

4. Only ECE should be launched in those schools, where there is the presence of plentiful space and trained teachers.

5. Trained Caregivers should be hired permanently. 
References

Acosta, A. G. (2018). The Successes \& Challenges of an Early Childhood Program Serving Children in Exceptional Circumstances: A Qualitative Case Study with Teachers, Administrators, \& Parents (Master published thesis). California State University, Long Beach.

Ahmad, N. R., Anjum, S., \& Rehman, S. (2015). Early childhood education in Pakistan: Issues \& challenges. International Journal of Science \& Research, 4(3), 413-415.

Arshad, M., \& Zamir, S. (2018). Situational Analysis of Early Childhood Education in Pakistan: Challenges \& Solutions. Journal of Early Childhood Care \& Education, 2(1), 135-149.

Bailey, D., Duncan, G., \& Odgers, C. (2017). Preschool can provide a boost, but the gains can fade surprisingly fast. The Washington Post. Retrieved from https://www.washingtonpost.com/ posteverything/wp/2017/02/17/preschoolcan-provide-a-boost-but-the-ga ins-can-fadesurprisingly-fast/?utm_term=.1ec207 $02 \mathrm{c} 2 \mathrm{~b} 4$.

Bhutta, E. (2020). Early Childhood Education, Mediation Analysis; A measurement of Factors Affecting Performance of Public Schools of Punjab Pakistan. Pakistan Journal of Education, 36(3).

Bishop, J., Maier, A., Melnick, H., \& Wechsler, M., (2016). The building blocks of high-quality early childhood education programs. Learning Policy Institute. Retrieved from https://learningpolicyinstitute.org/sites/default/files/product-files/Building Blocks_Early_Childhood_Education_04202016.pdf

Camilli, G., Vargas, S., Ryan, S., \& Barnett, S. (2010). Meta-analysis of the effects of early education interventions on cognitive \& social development. Teachers Record, 112(3), 579-620.

Creswell, J. W., \& Tashakkori, A. (2007). Differing perspectives on mixed methods research. Sage publications.

Farooq, M. S. (2018). Millennium development goals (MDGs) \& quality education situation in Pakistan at primary level. International Online Journal of Primary Education, 7(1), 1-23.

Franchett, E. E., Yousafzai, A. K., Rasheed, M. A., Siyal, S., Reyes, C. R., \& Ponguta, L. A. (2019). Experiences of community youth leaders in a youth-led early childhood education program in rural Pakistan. Zeitschrift für Psychologie. 27(2), 13-120.

Friedman-Krauss, A., Barnett, W., \& Nores, M. (2016, April). How much can high-quality universal pre-k reduce achievement gaps? Center for American Progress \& National Institute for Early Education Research. Retrieved from http://nieer. Org/wp-content/uploads/ 2017/01/NIEERAchievementGaps-report.pdf

Ghazi, S. R., Ajmal, M. \& Saeed, A. (2018). Effectiveness of early childhood education: A case study from the remote district of central Punjab. Journal of Early Childhood Care \& Education, 2(1), 75-86.

Gilbert, J.M. (2020). Cognitive Conditions \& Transfer of Professional Development Learning in Elementary School Teachers (Doctoral dissertation). Grand Canyon University Phoenix, Arizona.

Government of Punjab (2017). Punjab Early Childhood Education Policy 2017. SED/PMIU-PESRP.

Hunkin, E. (2018). If not quality, then what? The discursive risks in early childhood quality reform. Discourse: Studies in the Cultural Politics of Education, 40(6), 917-929.

Ismail, M., \& Awan, A. G. (2019). Impact of Early Childhood Education on Students'Enrollment in Schools in District Multan-Pakistan. Global Journal of Management, Social Sciences \& Humanities Vol 5 (4).

Jenkins, J. M, \& Duncan, G. J (2017). Do pre-kindergarten curricula matter? In J. V. Marcus-Jenkins \& G. Duncan, The current state of scientific knowledge on pre-kindergarten effects (Ch. 4). Washington, DC: Brookings Institution \& Duke University. Retrieved from https://archive.org/stream/ERIC_ED574393/ERIC_ED574393_djvu.txt

Johnson, L. (2016). Quality early childhood education \& care are a necessity for all children. Retrieved from https://aflcio.org/2016/7/12/quality-early-childhood education-\&-carenecessity-all-children

Kashar, C. (2018). Evaluation of a Climate Change Training Program for Local Government Employees (Doctoral Dissertation). Nova South-eastern University.

Khan, M. A. (2018). The status of early childhood education in Pakistan: Inside stories. Contemporary Issues in Early Childhood, 19(3), 310-317. 
Kimmel, P. A. (2020). The Effect of Collaborative Training on the Development of Professional Development Plans for Contract Instructors (Doctoral dissertation). Capella University.

Levi, J., Segal, L. M., Rayburn, J., Martin, A., \& Miller, A. F. (2015). A healthy early childhood action plan: Policies for a lifetime of well-being 2015. Washington, DC: Trust for America's Health.

Lipman, J. L. (2018). Role of Ready Leadership in a Head Start Preschool to Third Grade Continuum (Doctoral dissertation). California State University, Long Beach.

Mason, J. (2018). Qualitative researching. London: Sage.

Merriam, S. B. (2009). Qualitative Research: A guide to design \& implementation. San Francisco: John Wiley \& Sons.

Miles, M., Huberman, M., \& Saldaña, J. (2014). Qualitative data analysis: A methods sourcebook (3rd Ed.). Thousand Oaks: Sage

Miles, M. B., Huberman, A. M., \& Saldana, J. (2014). Fundamentals of qualitative data analysis. Qualitative data analysis: A methods sourcebook, 69-104.

National Association for the Education of Young Children. (1995). Quality, compensation, \& affordability. Retrieved from https://www.naeyc.org/sites/default/files/globally-shared/ downloads/PDFs/resources/position-statements/ PSQCA98.PDF

National Association for the Education of Young Children. (2015). developmentally appropriate practice \& the common core state standards: framing the issues. Research brief. Washington, DC: NAEYC.

National Association for the Education of Young Children. (2018). about accreditation. Retrieved from https://www.naeyc.org/ accreditation/early-learning/interested

Patton, M. Q. (2015). Qualitative research \& research methods (4th Ed.). Thousand Oaks: Sage Publications, Inc.

Pelot, T. J. (2018). A Quantitative Comparative Analysis of Early Learning \& Developmental Programs in High Poverty \& Low Poverty Counties in Missouri (Doctoral dissertation). Lindenwold University.

QAED. (2019, August 3). Building the wealth of nations; Early childhood care advance lifelong learning. Retrieved from http://qaed.edu.pk/

Saif, J., Inam, A., \& Abiodullah, M. (2020). Status of Katchi class about early childhood education policies \& practices in Punjab. Journal of Early Childhood Care \& Education, 4, 165-182

Saldaña, J. (2014). Coding \& analysis strategies. In The Oxford handbook of qualitative research. Oxford university press.

Schreier, M. (2012). Qualitative content analysis in practice. London: Sage Publications.

Shah, D., Haider, G, \& Taj, T. (2019). Causes of dropout rate at primary level in Pakistan. International Journal of Curriculum \& Instruction 11(2) 38-74.

Stevens, K., \& English, E. (2016). Does pre-k work: The research on ten early childhood programs-\& what tells us. Washington, DC: American Enterprise Institute for Public Policy Research

Thornton, K. (2019). Early Childhood Education Trainers' Knowledge \& Use of Anagogical Principles (Published Doctoral dissertation). Walden University: UK.

U.S. Department of Health \& Human Services \& U.S. Department of Education. (2016). Policy statement of family engagement: From the early years to the early grades. Washington, DC: Author.

UNESCO. (2018). Primary education for all children. Paris: UNESCO.

UNICEF. (2019). A World Ready to Learn: Prioritizing quality early childhood education. New York. Valentino, R., \& Stipek, D. J. (2016). Pre-K-3 alignment in California's educational system: Obstacles \& opportunities. Stanford, CA: Policy Analysis for California Education. 